\title{
The Exploration of Main Protection Configuration Schemes of Internal Short Circuit of Stator Windings for SFD250-20/7500 Motor-Generator
}

\author{
Chunyu Hu \& Yanling Lü \\ Harbin University of science and Technology, Harbin, Heilongjiang Province, China
}

\begin{abstract}
The main protection configuration scheme of internal short circuit for large generators is a prerequisite foundation for large generators to run with safety and reliability. Firstly, we sum up the type and the quantity of internal short circuit for stator windings for SFD250-20/7500 motor-generator. Then using the multi-loop analysis method, we calculate the current change rule of the short circuit branch and the non-shortcircuit branch when this generator is likely to happen to the internal short circuit of the stator windings. Furthermore, we figure up the sensitivity of all kinds of main protection configuration scheme. And we get the location of the dead zone of main protection operation which is easy to form. We ensure the configuration of main protection schemes by synthesizing all kinds of factors. Finally, we analyze and compare it with the actual protection scheme in one project.
\end{abstract}

KEYWORD: SFD250-20/7500 motor-generator; Internal short circuit; The dead zone of protection operation; Main protection scheme.

\section{INTRODUCTION}

When large generator occurs internal short circuit, there is greater short-circuit current in large generator, which is seriously threaten the normally safe operation (Gui lin. 2003) (Gui Lin et al, 2005). Meanwhile, it will cause enormous financial loss. In order to guarantee the quality of electric energy of power system and the stability of transmission, it is necessary to configure high-performance main protection scheme (Lv Yan-ling. 2015). Thus, we design a set of software for the recommendation of main protection of internal short circuit to satisfy the need of projects. We mainly make full use of the software to recommend main protection scheme for SFD25020/7500 motor-generator (Wen Ru-xin. 2014) (SUN Yu-guang et al, 2005). Then we get the applicability of the procedure about the recommendation of main protection by comparison and analysis with the scheme adopted by projects.

\section{THE BASIC PARAMETERS OF SFD250- 20/7500 MOTOR-GENERATOR}

The basic parameters of SFD250-20/7500 motorgenerator are as follows in Table 1.

Table 1. The basic parameters of SFD250-20/7500 motor-generator

\begin{tabular}{ccccc}
\hline Rated voltage & $15.78 \mathrm{kV}$ & Rated power & 250MW & The number of every branch's cycle \\
\hline Rated current & $10183.4 \mathrm{~A}$ & Winding types & Waving winding & The first pitch \\
Power factor & 0.9 & The number of stator slots & 312 & The second pitch \\
Rated frequency & $50 \mathrm{~Hz}$ & The number of pole pairs & 20 & The number of every score's branch \\
\hline
\end{tabular}




\section{THE STATISTIC AND ANALYSIS OF THE INTERNAL SHORT CIRCUIT}

Using the procedure of short circuit statistics, we know for the number of the internal short circuit which is likely to occur in the stator winding of this electric machine.

There are 312 kinds of short circuit between up and down in the stator bar insulation. There are 48 kinds of faults which occur in the different phase and the same number, at $33.33 \%$ of interphase short circuit number. There are 96 kinds of short circuit which happens in the different branch, at $66.67 \%$ of interphase short circuit number. There are 9048 kinds of short circuit in the cross of stator slots, which occur in the same phase and the different number is at $5.57 \%$.

\section{THE CALCULATION OF SENSITIVITY}

Based on current design method of main protection of internal short circuit from DL/T684-2012 of Guide of calculating settings of relay protection for large generator and transformer, we take coefficient of correction of generator, namely, sensitivity as the criterion. We think that main protection can be sensitive to act.

$$
K_{\text {sen }}=I_{d}^{*} / I_{o p}^{*}
$$

Where $I_{d}{ }^{*}$ is the differential current of all kinds of main protection, and $I_{o p}{ }^{*}$ is the homologous operation current, which is relative to the selection of protection criterion.

\section{THE CONFIGURATION OF MAIN PROTECTION SCHEME OF INTERNAL SHORT CIRCUIT FOR SFD250-20/7500 MOTOR-GENERATOR}

\subsection{The outgoing mode of stator winding branch}

For SFD250-20/7500 generator, according to 4, the number of the branch of stator winding, we can divide stator winding into two ways. One is two-group branches to extract and the other is three-group branches to extract. Two-group branches have two kinds of branch grouping modes, 12-34(I) and 1324(II). Three-group branches are divided into 3 parts, one, two and one branch, having two kinds of branch grouping modes, 1-2 -34(III) and 1- 24$3(\mathrm{IV})$. We respectively cite figure 1 to illustrate one way of two-group branches to extract (12-34).

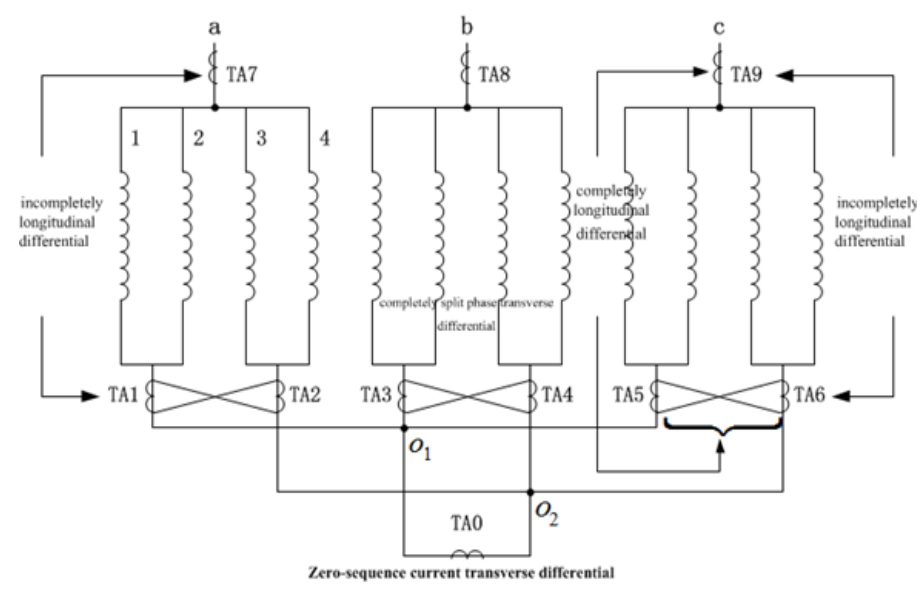

Figure 1. The mode of two-group branches to extract I(12-34)

\subsection{Performance analysis of protection that} SFD250-20/7500 motor-generator gets from all kinds of main protection

The preference has analyzed the performance of main protection. Then, we analyze the performance of four main protections for SFD250-20/7500 motor-generator.

Table 2, shows that Zero-sequence current transverse differential II(13-24) and Zero-sequence current transverse differential IV.2(1-24-3) have the most number of sensitive operation, which is up to 9319, and have 41 no action. The rate of action is $99.57 \%$.

Table 3 shows that completely split phase transverse differential II has the most number of sensitive operation, which up to 9319 , and have 41 no action. The rate of action is up to $100 \%$.

When the three-phases leads of generator terminal occur short circuit, various transverse differential don't act. So a longitudinal differential protection must be added. That how many sets we should add and how many we should choose branch current of neutral point in every set of longitudinal differential protection, this should be calculated accurately.

\section{THE RECOMMENDATION OF MAIN PROTECTION CONFIGURATION SCHEMES}

In order to give consideration to the short of stator winding short circuit and the generator terminal short circuit, main protection configuration schemes must conclude transverse differential and longitudinal differential to form one transverse and one longitudinal primary pattern. With our design experience, we mainly consider the primary pattern formed by completely split phase transverse differential +two sets of incompletely longitudinal differential and completely split phase transverse differential + completely longitudinal differential at the situation of two branches to extract on average. However, we mainly consider the primary pattern formed by in- 
completely split phase transverse differential + two sets of incompletely longitudinal differential at the situation of two branches to extract on average. The primarily recommended main protection scheme is as follows in Table 5.

Table 2. The statistic of sensitivity of all kinds of Zero-sequence current transverse differential protection for various internal short circuit short circuits at the situation of network no-load running of SFD250-20/7500 motor-generator (all 9360) (turns)

\begin{tabular}{|c|c|c|c|c|c|c|c|c|}
\hline \multirow[b]{3}{*}{$\begin{array}{l}\text { Zero-sequence current transverse differential } \\
\text { I(12-34) }\end{array}$} & \multicolumn{4}{|c|}{$\begin{array}{l}\text { The number of sensitive opera- } \\
\text { tion }\left(\mathrm{K}_{\text {sen }} \geq 1.5\right)\end{array}$} & \multicolumn{4}{|c|}{$\begin{array}{l}\text { The number of not opera- } \\
\text { tion }\left(\mathrm{K}_{\mathrm{sen}}<1.5\right)\end{array}$} \\
\hline & SPSB $^{*}$ & SPDB $^{*}$ & Interphase & Total & SPSB & SPDB & Interphase & Total \\
\hline & 504 & 2226 & 6389 & 9119 & 0 & 150 & 91 & 241 \\
\hline $\begin{array}{l}\text { Zero-sequence current transverse differential } \\
\text { II(13-24) }\end{array}$ & 504 & 2376 & 6439 & 9319 & 0 & 0 & 41 & 41 \\
\hline $\begin{array}{l}\text { Zero-sequence current transverse differential } \\
\text { III.1(1-34-2) }\end{array}$ & 504 & 2037 & 6316 & 8857 & 0 & 339 & 164 & 503 \\
\hline $\begin{array}{l}\text { Zero-sequence current transverse differential } \\
\text { III.2(1-34-2) }\end{array}$ & 504 & 2226 & 6389 & 9119 & 0 & 150 & 91 & 241 \\
\hline $\begin{array}{l}\text { Zero-sequence current transverse differential } \\
\text { III.3(1-34-2) }\end{array}$ & 504 & 2067 & 6171 & 8742 & 0 & 309 & 165 & 474 \\
\hline $\begin{array}{l}\text { Zero-sequence current transverse differential } \\
\text { IV.1(1-24-3) }\end{array}$ & 504 & 2037 & 6316 & 8857 & 0 & 339 & 164 & 203 \\
\hline $\begin{array}{l}\text { Zero-sequence current transverse differential } \\
\text { IV.2(1-24-3) }\end{array}$ & 504 & 2376 & 6439 & 9319 & 0 & 0 & 41 & 41 \\
\hline $\begin{array}{l}\text { Zero-sequence current transverse differential } \\
\text { IV.3(1-24-3) }\end{array}$ & 504 & 2007 & 6308 & 8819 & 0 & 369 & 172 & 541 \\
\hline
\end{tabular}

SPSB is the same phase and the same branch, SPDB is the same phase and the different branch.

Table 3. The statistic of sensitivity of all kinds of split phase transverse differential protection for various internal short circuit short circuit at the situation of network no-load running of SFD250-20/7500 motor-generator (all 9360) (turns)

\begin{tabular}{|c|c|c|c|c|c|c|c|c|}
\hline \multirow[b]{3}{*}{$\begin{array}{l}\text { Completely split phase transverse differential } \\
\qquad \mathrm{I}(12-34)\end{array}$} & \multicolumn{4}{|c|}{$\begin{array}{l}\text { The number of sensitive opera- } \\
\operatorname{tion}\left(\mathrm{K}_{\mathrm{sen}} \geq 1.5\right)\end{array}$} & \multicolumn{4}{|c|}{$\begin{array}{l}\text { The number of not opera- } \\
\operatorname{tion}\left(\mathrm{K}_{\mathrm{sen}}<1.5\right)\end{array}$} \\
\hline & SPSB & SPDB & Interphase & Total & SPSB & SPDB & Interphase & total \\
\hline & 504 & 2340 & 6480 & 9324 & 0 & 36 & 0 & 36 \\
\hline $\begin{array}{l}\text { Completely split phase transverse differential } \\
\text { II(13-24) }\end{array}$ & 504 & 2376 & 6480 & 9360 & 0 & 0 & 0 & 0 \\
\hline $\begin{array}{l}\text { Incompletely split phase transverse differential } \\
\text { III(1-34-2) }\end{array}$ & 504 & 2352 & 6472 & 9328 & 0 & 24 & 8 & 32 \\
\hline
\end{tabular}

Table 4 The statistic of sensitivity of all kinds of completely longitudinal differential protection for various internal short circuit short circuit at the situation of network no-load running of SFD250-20/7500 motor-generator (all 9360) (turns)

\begin{tabular}{ccccccccc}
\hline & \multicolumn{3}{c}{ The number of sensitive operation $\left(\mathrm{K}_{\mathrm{sen}} \geq 1.5\right)$} & \multicolumn{3}{c}{ The number of not operation $\left(\mathrm{K}_{\text {sen }}<1.5\right)$} \\
\cline { 2 - 9 } K3 & SPSB & SPDB & SPSB & SPDB & SPSB & SPDB & SPSB & SPDB \\
& 0 & 0 & 6480 & 6480 & 504 & 2376 & 0 & 2880 \\
\hline
\end{tabular}

Table 5. The main protection scheme preliminarily recommended

Scheme II.1(13-24) $\quad$ Completely split phase transverse differential +two sets of incompletely longitudinal differential(K01+212)

Scheme II.2(13-24) Split phase transverse differential +two sets of incompletely longitudinal differential+ Zero-sequence current transverse differential $(\mathrm{K} 01+11+212)$

Scheme II.3(13-24) Split phase transverse differential + completely longitudinal differential(K10+3)

Scheme II.4(13-24) Split phase transverse differential + completely longitudinal differential + Zero-sequence current transverse differential $(\mathrm{K} 01+10+3)$

Scheme III.1(1-34-2) Incompletely split phase transverse differential +two sets of incompletely longitudinal differen$\operatorname{tial}(\mathrm{K} 11+212)$

Scheme III 2(1-34-2) Zero-sequence current transverse differential + incompletely split phase transverse differential + two sets of incompletely longitudinal differential $(\mathrm{K} 01+11+212)$

Scheme III.3(1-34-2) Two sets of Zero-sequence current transverse differential + incompletely split phase transverse differential+ two sets of incompletely longitudinal differential $(\mathrm{K} 02+11+212)$

Scheme IV.1(1-24-3) Incompletely split phase transverse differential + two sets of incompletely longitudinal differen$\operatorname{tial}(\mathrm{K} 11+212)$

Scheme IV.2(1-24-3) Zero-sequence current transverse differential + incompletely split phase transverse differential + two sets of incompletely longitudinal differential $(\mathrm{K} 01+11+212)$

Scheme IV.3(1-24-3) Two sets of Zero-sequence current transverse differential + incompletely split phase transverse differential+ two sets of incompletely longitudinal differential $(\mathrm{K} 02+11+212)$ 
By the comparison of feasible scheme of main protection of internal short circuit for SFD25020/7500 motor-generator, we consider the rate of correct operation and the degree of doubleprotection. The analysis is as follow in Table 6 .

Table 6 . The analysis of performance of main protection

\begin{tabular}{lll}
\hline $\begin{array}{l}\text { Protection } \\
\text { schemes }\end{array}$ & $\begin{array}{l}\text { Correct opera- } \\
\text { tion rate }\end{array}$ & $\begin{array}{l}\text { The degree of } \\
\text { double-protection }\end{array}$ \\
\hline Scheme II.1 & $100 \%$ & $99.78 \%$ \\
Scheme II.2 & $100 \%$ & $100 \%$ \\
Scheme II.3 & $100 \%$ & $69.23 \%$ \\
Scheme II.4 & $100 \%$ & $100 \%$ \\
Scheme III.1 & $99.78 \%$ & $99.68 \%$ \\
Scheme III.2 & $99.81 \%$ & $99.71 \%$ \\
Scheme III.3 & $99.81 \%$ & $99.52 \%$ \\
Scheme IV.1 & $99.97 \%$ & $99.90 \%$ \\
Scheme IV.2 & $99.67 \%$ & $99.67 \%$ \\
Scheme IV.3 & $99.97 \%$ & $99.94 \%$ \\
\hline
\end{tabular}

Through the performance analysis of any four kinds of main protection, we draw the conclusion that any one scheme of III is not inferior to scheme II and IV. With the analysis of Zero-sequence current transverse differential and split phase transverse differential, we can get the protection effect of scheme I is not good, which should be directly rejected by comparing with scheme II and IV. But due that the number of main protection of scheme $I$ is less, we should consider it combined practically. Scheme 2 and scheme 4 is identical, but scheme 2 has one more set of main protection than scheme 4 . We recommend scheme 2 and reject scheme 3 . Compared with scheme 2 which has one more set of main protection but not meets the demand that the more main protection is, the better the sensitivity is, scheme 1 just has 3 sets of main protection. So we suppose scheme 1 more suitable than scheme 2 .

It is sensitive to act in 9360 kinds of internal short circuit for scheme 1 of II, whose correct operation rate is up to $100 \%$, and whose degree of doubleprotection is highly up to $99.78 \%$. The extracting mode of neutral point side that neutral point need add 6 external line. Scheme 4 has 3 sets of main protection that has Zero-sequence current transverse differential, which need current transformer single added. Scheme 3 of IV needs two sets of current transformer. It increases the cost of main protection, but the protection performance just improves to $0.192 \%$.

\section{CONCLUSION}

The design of the main protection configuration scheme of internal short circuit for generators is a complicated systematic problem about engineering optimization design, which must be considered to science and practicality of design. On the premise of obviously not decreasing the performance of main protection configuration scheme, the extraction of generator neutral point branch must consider whether the generator's structure and manufacturing technology is convenient and whether it is beneficial to simplify protection scheme and how to reduce the hardware investigation. According to the index of protection performance, the rate of correct action is more important than the degree of double-protection. In order to pose potential problems for the design of structure, manufacture and installation of one generator, we give priority to the scheme having simpler configuration II.1. It is easy to configure for this kind of scheme.

\section{REFERENCES}

Gui lin. 2003. Research on Optimum Design of Main Protection Configuration Scheme for Large Generators[D].

Gui Lin, WANG Wei-jian. 2005. Research Summarization on Design of Main Protection Configuration Scheme for Hydrogenerator of Three Gorges Right Bank Power Station. Automation of Electric Power Systems29(13): 69- 75

Lv Yan-ling. 2015. Discussion of main protection configuration schemes for Stator internal short circuits in SF60042/1308 generator. International Journal of u- and e- Service, Science and Technology 8(5):337-344

SUN Yu-guang, WANG Xiang-heng, GUI Lin. 2005. Optimization Design of Main Protection Configuration Scheme for Internal Faults of Generator with Even Multi-Branches. Automation of Electric Power Systems29 (12): 83-92.

Wen Ru-xin. 2014. Research of main protection configuration scheme for internal short circuit of large generators[D]. 